\title{
Spatial and temporal characteristics of wind and wind power off the coasts of Brittany
}

\author{
Abderrahim Bentamy*, Denis Croize-Fillon \\ Laboratoire d'Océanographie Spatiale, IFREMER, France \\ *: Corresponding author : Abderrahim Bentamy, email address : abderrahim.bentamy@ifremer.fr
}

\begin{abstract}
:
The main objective of this paper is to thoroughly examine the remotely sensed wind characteristics around the coasts of Brittany as well as some more specific areas. The offshore wind power potential is then assessed. To achieve this objective, information on wind speed and direction with sufficient spatial and temporal sampling under all weather conditions and during day and night is required. This study uses more than 12 years (December 1999-December 2012) of consistent remotely sensed data retrieved from the ASCAT and QuikSCAT scatterometers to estimate the conventional moments and associated wind distribution parameters. The latter are comparable to wind observations from meteorological stations. Furthermore, combining in-situ and scatterometer wind information enables an improved assessment of the spatial and temporal wind structures at specific locations of interest to be made. The wind statistical results are used to study the spatial and temporal patterns of the wind power. Although the main parameters characterizing wind power potential such as mean, variability, maximum energy, wind speed and intra-annual exhibit seasonal features, significant inter-annual variability is also depicted. Furthermore, differences are found between the wind power estimated for northern and for southern Brittany.
\end{abstract}

\section{Highlights}

Using scatterometer retrievals for MRE purposes. Spatial and temporal structures of wind off Brittany coasts. Spatial and temporal characteristics of wind energy.

Keywords: Wind ; Energy ; Scatterometer ; Remote sensing ; Brittany

\section{Introduction}

Several countries have set up ambitious programmes aiming to investigate the capability of renewable marine energy operational productions. In France, the "Grenelle de la Mer" (http://www.legrenelleenvironnement.fr/) suggests that marine energy derived from various platforms and sources would provide $3 \%$ of the total required energy and could reach a production level of $6000 \mathrm{MW}$ in 2020. Such an objective requires precise knowledge of the parameters characterizing the oceanographic and atmospheric parameters at various spatial and temporal scales. In particular, it means the 
31acquisition and analysis of a significant sample of the resource of primary interest, such as wind 32(speed and direction), waves (significant heights, directions, peaks, and spectra), currents and 33stratification (depth of the mixed layer). Precise knowledge of these parameters with high accuracy 34and spatial and temporal resolution is necessary for the proper design of structures and to estimate 35the environmental risks.

36 Among the sources of marine renewable energy (MRE), wind energy exploitation is growing 37fast. Even though wind farm installations are still costly, their developments meet the public 38awareness about environmental issues, and the energy produced would contribute to the regional 39energy supply and security. The project called "France Energies Marines” (http://www.france40energies-marines.org/) is one the main programmes aiming to assess wind resource requirements. 41Some experimental sites located off the coasts of France have been selected to achieve this. Here, 42the areas of interest are located offshore of Brittany in the north-west of France (Figure 1). These 43areas are characterized by one of the most important wind energy resources in France. The 44dominant winds over this region are westerly winds. Furthermore, high winds reaching 50-60m/s 45can occur during the winter season due to westerly storms.

46 In this study, wind resources are mainly derived from scatterometers which provide surface 47wind vector information over the global oceans. Various attempts regarding the evaluation of wind 48energy potential for different oceanic areas based on remotely sensed data have been carried out 49(e.g. [1], [2], [3]). To our best knowledge, there are no previous publications focusing on the 50analysis of wind energy potential for the coasts of Brittany based on scatterometer retrievals. 51Various scatterometers can be used to assess the wind resources, such as ERS-1 (1991 - 1996), 52ERS-2(1995 - 2011), NSCAT (1996-1997), Seawinds onboard QuikSCAT (1999 - 2009), 53Seawinds on board ADEOS-2 (2003), ASCAT onboard METOP-A (2006 - Present). Here, only 54retrievals from QuikSCAT and from ASCAT are used. Both winds compare well, and their 55consistency has been established in recent work [4]. Remotely-sensed wind data with a high spatial 56resolution of $12.5 \mathrm{~km} \times 12.5 \mathrm{~km}$ are available. Furthermore, coastal winds are also retrieved from 57ASCAT measurements.

58 Here, the distribution of wind resources between the near-shore and offshore regions around 59Brittany are evaluated using twelve years of remotely-sensed data (December 1999 - December 602012). Such a long time series is extremely valuable to assess the wind regimes and wind energy 61related quantities over extended oceanic areas. It is also helpful to highlight the most appropriate 62locations for energy production and thus for wind turbine installation.

63 The paper contents are as follows: in section 2 the data used, the quality checks, and the 64required wind corrections used in the study are described. Section 3 deals with the comparisons 
65between in-situ and remotely-sensed winds. The analyses of the distribution of wind and the related 66wind power are presented in sections 4 and 5, respectively. The conclusions are listed in section 6. 67

\section{DATA}

\subsection{Remotely sensed data}

70 The scatterometer principle is described in many scientific publications. Scatterometer 71antennae emit microwaves towards the surface, which are scattered by short sea waves 72(capillary/gravity waves). The latter are strongly related to changes in surface winds. Surface wind 73speeds and directions are available over scatterometer swaths with various orbit and spatial 74resolution characteristics. This study relies on winds retrieved from SeaWinds scatterometer 75onboard QuikSCAT satellite, and from Advanced Scatterometer (ASCAT) onboard Metop-A 76satellite. Readers may found complete descriptions of the two scatterometers and of the associated 77retrievals in [9] for QuikSCAT, and on the SAF OSI website http://www.knmi.nl/scatterometer/ for 78ASCAT. They provide valuable information related to instrument physics, retrieval and ambiguity 79removal methods, rain detection and flagging techniques, and quality control procedures. Briefly, 80QuikSCAT is a rotating antenna with two differently polarized emitters: the H-pol with incidence 81 angle of $46.25^{\circ}$ and $\mathrm{V}$-pol with incidence angle of $54^{\circ}$. The inner beam has a swath width of about $821400 \mathrm{~km}$, while the outer beam swath is $1800 \mathrm{~km}$ width. The QuikSCAT scatterometer is a Ku band 83radar, therefore rain has a substantial influence on its measurements. Previous studies showed that 84the rain impact may attenuate the scatterometer signal resulting in wind speed underestimation, or 85raindrop impacts may change the sea surface shape resulting in overestimation of the retrieved 86winds. Results from [5] indicate that rain backscatter contributes to the scatterometer signal 87resulting generally in wind speed overestimation; intense rain causes overestimates of $15-20 \mathrm{~m} / \mathrm{s}$ for 88cross-track winds. So, rain attenuation dominates over rain backscatter for extreme winds. 89QuikSCAT wind products include several rain flags determined from the scatterometer observations 90and from the collocated radiometer rain rate onboard other satellites. This study uses new 91QuikSCAT wind retrievals $\quad$ Qulled 92(ftp://podaac.jpl.nasa.gov/OceanWinds/quikscat/preview/L2B12/v3/). They are made available by Jet 93Propulsion Laboratory (JPL)/ Physical Oceanography Distributed Active Archive Center 94(PODAAC) scientific team [6]. QuikSCAT V3 products are calculated through use of a geophysical 95model function ensuring the consistency with winds retrieved from microwave radiometers such as 96Special Sensor Microwave/Imager (SSM/I) and WindSat [7].QuikSCAT wind retrievals are 97provided over swaths at a Wind Vector Cell (WVC) of $12.5 \mathrm{~km}$ spatial resolution. This new 
98scatterometer product is assumed to improve wind speed performance in rain and at high wind 99speed conditions.

100

ASCAT has an engineering design that is quite different from QuikSCAT. Rather than a 101rotating antenna it has a three beam antenna looking $45^{\circ}$ (fore-beam), 90 (mid-beam), $135^{\circ}$ (aft102beam) of the satellite track, which together sweep out two $550 \mathrm{~km}$ swaths on both sides of the track. 103The incidence angle varies in the range $34^{\circ}-64^{\circ}$ for the outermost beams and $25^{\circ}-53^{\circ}$ for the mid104beam, giving Bragg wavelengths of 3.2-5.1cm and 3.6-6.8 cm. Here we use three types of ASCAT 105products: level 2b ASCAT near real time at 25x25 km² resolution, level 2b125 product available 106with higher spatial resolution of $0.125^{\circ} \times 0.125^{\circ}$ along and cross swath, and the product providing 107coastal information, referred to as the ASCAT coastal product, which is available with a resolution 108 of $0.125^{\circ} \mathrm{x} 0.125^{\circ}$. The products are available from Eumetsat Ocean Sea Ice Satellite Application 109Facility (OSI/SAF) (http://www.osi-saf.org/). Details of calibration, validation, and processing schemes 110can be found at (http://www.knmi.nl/scatterometer/). Hereafter, the three ASCAT wind products are 111referenced as ASCAT25 (available from April 2007 through to present), ASCAT125 (February 1122009 - present), and ASCAT_coast (August 2010 - present), respectively. Comparisons to 113independent mooring and shipboard observations by [8] and [9] show that ASCAT25 wind speed 114and direction have rms difference values (in-situ minus scatterometer) of about $1.40 \mathrm{~m} / \mathrm{s}$, and $18^{\circ}$, 115respectively. A similar validation procedure has been applied to ASCAT125 and ASCAT_coast to 116assess the quality of wind speed and direction retrievals [10]. The findings indicate that ASCAT 117high resolution products have accuracy similar to the low resolution data. For instance the rms 118differences (buoy minus scatterometer winds) of zonal as well as meridional components are about $1191.50 \mathrm{~m} / \mathrm{s}$.

120 The accuracy of the QuikSCAT V3 data is determined through various comparisons with 121buoy wind measurements, QuikSCAT V2, and ASCAT retrievals. The main findings (not shown) 122are the comparison results are similar to those obtained previously (e.g. [4]). QuikSCAT V3 and 123QuikSCAT V2 exhibit similar comparison results versus buoys. ASCAT and QuikSCAT V3 124statistics are of the same order as ASCAT and QuikSCAT V2. Similar agreements and 125discrepancies characterizing ASCAT and QuikSCAT V2 comparisons are found for ASCAT and 126QuikSCAT V3. QuikSCAT V3 are improved when compared with the earlier results reported by 127[4]. We expect that the remaining discrepancies between the C-band radar and the Ku-band radar 128wind retrievals are inherent in their characteristics, such as the penetrating wavelengths of the 129radars and differences in the backscatter from surface waves at different wavelengths. Such effects 130would be pronounced in low wind speed regimes and at certain values of SST.

131 Wind speeds derived from ASCAT and from QuikSCAT are corrected with respect to results 132which assessed the coherency between C-and and Ku-band retrievals ( [3], [11]). Briefly, only 
133QuikSCAT rain-free data associated with multidimensional rain probabilities ([12]) lower than 0.05 134are selected. For ASCAT wind corrections, the bias $d W$ (eq. (1)) was determined by fitting the mean 135difference between QuikSCAT and ASCAT winds as a function of ASCAT wind speed $\left(W_{A S}\right)$ and 136azimuth direction $(\varphi)$ ranges.

$137 d W=\sum_{m=0}^{m=3} P_{5}^{m}\left(W_{A S}\right) \cos (m \phi)$,

138 Where the coefficients $P_{5}^{m}\left(W_{A S}\right)$ are assumed to be fifth order polynomials of ASCAT wind 139speed.

140 Hereafter, ASCAT wind speed refers to $W_{A S}+d W$.

141 Figure 1 shows the spatial distribution of the sampling length of wind speed observations 142derived from scatterometers QuikSCAT and ASCAT during the period December 1999 through 143December 2012. It is shown at grids of 0.125 degree in longitude and latitude. ASCAT retrievals 144available with a swath spatial resolution of 0.25 degree are attributed to the closest $0.125^{\circ}$ grid 145point. As expected, the highest and lowest observation numbers are found offshore and near-shore, 146respectively. Most of the data located $25 \mathrm{~km}-12.5 \mathrm{~km}$ from coasts are derived from ASCAT coastal 147product.

\subsection{In-situ data}

149 To assess the wind statistics calculated from remotely-sensed wind retrievals along Brittany's 150coasts, anemometer 10-m wind measurements are used for comparison purposes (Figure 2). Indeed, 151they are assumed to capture fine-scale local winds that may be influenced by orography and local 152air-sea interaction impacts. Table 1 shows their WMO identification and their locations. They are 153land-based operational meteorological stations located near shores and managed by Météo-France 154(MF). Although the stations have been operating for several years, only winds measured during the 155period March 2008 through August 2012 are available for this study. Winds from stations are 156available at 10-m height and every 30 minutes, one hour or three hours depending on the station. 157Since scatterometers provide equivalent neutral winds (ENWs) at 10-m above the sea surface, in158situ winds should be corrected according to the atmospheric stability. This correction is performed 159using COARE3.0 model [13].

160 The entire station dataset are checked for erroneous values. Values of about $0 \mathrm{~m} / \mathrm{s}$ or 161exceeding 50m/s are not considered in this study. The outliers of winds reported from each station 162are first detected based on the use of the daily averaged wind estimates. The latter are estimated 163every day as mean values of the consecutive raw data available from 00h:00 through 21h:00UTC 164every 3 hours. The daily variability is calculated as standard deviation values (STD). Each "raw" 
165observation exceeding the daily mean value by a factor of three times the STD is removed as an 166outlier.

167

\section{IN-SITU AND SCATTEROMETER WIND COMPARISONS}

169 This study does not deal with the determination of the accuracy of scatterometer retrievals 170based on the use of station measurements. The main aim of the in-situ and scatterometer wind 171comparisons is to highlight the agreements and discrepancies between the two sources. The results 172are first used to support the comparisons between wind distributions determined from in-situ and 173from remotely-sensed data and to assess how scatterometer retrievals may represent near-shore 174surface winds.

\subsection{Collocation procedure}

176 Station and scatterometer wind comparisons require first the data to be collocated in space 177and time. Indeed, the spatial and temporal wind variability derived from in-situ and from remotely178sensed data may lead to significant differences. Therefore, the collocation criteria should be defined 179with respect to the time and space characteristics. They are estimated based on the method of 180Crosby et al. [14] dealing with the determination of spatial and temporal correlation coefficients: 181

182

$$
\rho^{2}(X, \delta t)=\rho^{2}\left(\operatorname{Wst}\left(X_{0}, 0\right), W s c(X, \delta t)\right)
$$

$$
\rho^{2}\left(X_{0}, \delta t\right)=\rho^{2}\left(W s t\left(X_{0}, 0\right), W s t\left(X_{0}, \delta t\right)\right)
$$

185indicate wind speed from stations and from scatterometers, respectively. Wst $\left(\mathrm{X}_{0}, \delta \mathrm{t}\right)$ and $\mathrm{Wsc}(\mathrm{X}, \delta \mathrm{t})$ 186are wind speed time series at location $\mathrm{X}(\mathrm{x}, \mathrm{y})$ shifted $\delta \mathrm{t}$ hours from stations and from 187scatterometers, respectively. $\mathrm{X}_{0}$ states for station location. Equation (2) leads to the characterization 188of the spatial and temporal structures, whereas equation (3) estimates the temporal cross-correlation 189of station time series.

190 For lag time, $\delta \mathrm{t}$, of one hour, $\rho^{2}\left(\mathrm{X}_{0}, \delta \mathrm{t}\right)$, estimated for each in-situ wind speed time series, 191varies between 0.86 and 0.90 . The highest time correlations are found at Ouessant (07100) and 192Penmarc'h (07200) both stations being the most exposed to prevailing winds (Figure 2). Increasing 193the lag time to two or three hours leads to a decrease in the correlation variation by a factor of about $1946 \%$ and $14 \%$, respectively. For instance, for $\delta$ t of 2 hours, only correlations $\rho^{2}(\mathrm{X}, \delta \mathrm{t})$ (eq. 3) 195estimated at Ile de Groix (07203), Ouessant (07100), and Pointe du Raz (07103) exceed a threshold 196of 0.80. Selecting a lag time of less than 1 hour, the spatial correlation between each station and 197remotely sensed data (Wst and Wsc (eq. (2))), calculated as a function of spatial separation 
198(distance between $\mathrm{X}_{0}$ and $\mathrm{X}$ ), are shown in Figure 3. It indicates that spatial correlation values are 199lower than 0.80 for distances exceeding 100km. At stations Ile de Batz (07116), and Saint Nazaire 200(07216) correlations do not reach 0.80 even for shorter distances. Ile de Batz is a land station 201located about 600 meters inland. Saint Nazaire is located in relatively narrow inlets compared to 202the scatterometer WVC spatial resolution (about $25 \mathrm{~km}^{2}$ or $12.5 \mathrm{~km}^{2}$ ). The spatial correlations found 203for distances lower than 25km at Ouessant (07100), Penmarc'h (07200), and Pointe du Raz (07103) 204are of the same order as the temporal correlation $\rho^{2}\left(X_{0}, \delta t\right)$ calculated for one hour time lag. Further 205investigations are performed to assess the spatial and temporal correlations according to wind 206direction sectors. For a time lag of 1 hour, the highest spatial correlations are found for westerly 207winds (most prevailing regional wind condition) at all stations, except at Ile de Batz (07116). 208Indeed, their values exceed 0.80 and reach 0.95 for spatial distances ranging between $12.5 \mathrm{~km}$ and $209100 \mathrm{~km}$. Better spatial correlation results are obtained at Ile de Batz for easterlies. Only correlations 210estimated at Ouessant have values exceeding 0.80 for all sectors and for separations less than $211100 \mathrm{~km}$.

212 For this study only spatial and temporal separations leading to correlations exceeding 0.80 are 213retained. Indeed, the threshold 0.80 meets the correlation result characterizing the comparison 214between buoy, moored off European coasts, and scatterometer wind speeds (e.g [8]). Following this 215analysis of spatial and temporal correlations, stations 07116 and 07216 are excluded and the 216procedure aiming to collocate in-situ and scatterometer winds is performed based on the space and 217time criteria of $25 \mathrm{~km}$ and 1 hour, respectively.

\subsection{Comparison results}

219 Figure 4 shows results illustrating the comparisons of meteorological station and ASCAT 220scatterometer wind speeds during the period 2008 - 2012. The latter are from ASCAT retrievals 221since they are available throughout 2008 - 2012 period. Similar results are obtained for station and 222QuikSCAT wind comparisons during their overlapping period (January 2008 - November 2009). 223Statistical parameters of scatterometer retrievals against station measurements are presented in 224Table 2. The results are provided for all collocated data (Figure 4a) as well as for collocated data at 225Ouessant station (Figure 4b), as the results found in the previous section (3.1) indicate that the best 226agreement between in-situ and scatterometer wind speeds is found at this specific station. Although 227the comparison for all collocated data (Figure 4a) indicates quite good agreement between the two 228sources, the scatterometer wind speeds tend to be overestimated with respect to in-situ 229 measurements. The mean bias is about $-0.80 \mathrm{~m} / \mathrm{s}$ and the associated standard deviation (STD) is $230 \mathrm{about} 2.20 \mathrm{~m} / \mathrm{s}$. This overestimation is not found at Ouessant station (Figure $4 \mathrm{~b}$ ), however, where the 231bias and STD are $0.07 \mathrm{~m} / \mathrm{s}$ and $1.66 \mathrm{~m} / \mathrm{s}$, respectively. The latter meet the statistical results aiming to 
232characterize retrieval quality based on collocated moored buoy and scatterometer winds (e.g. [8]). 233Therefore, the larger departures found when all collocated data are selected are the result of 234expected differences between onshore and coastal wind speeds (e.g. [15]). The frequency of 235occurrence of calm and light winds tends to be larger at onshore than nearshore sites. For instance, 236the percentage of wind speeds lower than $5 \mathrm{~m} / \mathrm{s}$ are about $37 \%$ and $25 \%$ for in-situ and scatterometer 237winds, respectively. Only the station Pointe du Raz (07103) shows a higher mean wind speed than 238the scatterometer, which is the result of more high wind conditions. Indeed, the 90 and 95 239percentiles are of $13 \mathrm{~m} / \mathrm{s}$ and $15 \mathrm{~m} / \mathrm{s}$, respectively, whereas they do not exceed $11 \mathrm{~m} / \mathrm{s}$ and $13 \mathrm{~m} / \mathrm{s}$ for 240the rest of stations. Investigating station and scatterometer wind speeds as a function of wind 241direction sectors disclosed differences in statistical results. For instance, the best results (low bias 242and STD, and high correlation) are found for stations 07207, 07203, 07100, 07200 in the presence 243of westerlies. Further comparisons based on monthly-averaged wind speed time series calculated 244from collocated data also reveal that the seasonal features of scatterometer-derived retrievals match 245those of in-situ data. Both indicate that the maximum and minimum winds occur during the periods 246November - January and June-August, respectively.

\section{SCATTEROMETER WIND DISTRIBUTIONS}

248 The results provided in section above, based on analysis of time- and space-collocated data, 249indicate that remotely-sensed winds realistically represent local winds occurring off the coasts of 250Brittany. Here we focus on the determination of wind speed distributions using only scatterometer 251winds from the period December 1999 - December 2012.

\subsection{Influence of scatterometer sampling scheme}

253 One of the main issues is that the remotely-sensed data are only available from morning and 254afternoon passes: 4h-6h UTC and 17h-19h UTC for QuikSCAT; and 9h-11h UTC and 20h-22h 255UTC for ASCAT. Therefore, the impact of such temporal sampling schemes should be studied prior 256the determination of wind speed distribution from satellite observations. To achieve such objective, 257data from in-situ sations are used. At each station, statistical parameters such as the mean, median, 258STD, skewness (Skew), kurtosis (Kur), $10\left(\mathrm{P}_{10}\right), 90\left(\mathrm{P}_{90}\right)$, and $95\left(\mathrm{P}_{95}\right)$ percentiles are calculated 259based first on all valid data, and secondly on only data occurring within one hour of scatterometer 260overpasses (Table 3). The two calculations are shown for each station on the top and bottom row, 261respectively. Both show similar wind speed distributions at each in-situ location. Selection of 262station data associated with scatterometer overpasses shows wind distributions which are slightly 263positively biased with respect to the distributions estimated from the full dataset. However, the bias 
264is small, about $0.10 \mathrm{~m} / \mathrm{s}$. Furthermore, using the Student's t-distribution test, the two wind speed 265means estimated for stations Ile de Batz(07116), Ile de Groix(07203), Ouessant(07100), Pointe du 266Raz(07103), Saint Nazaire(07216) are comparable at the 95\% confidence level.

\subsection{Spatial wind distribution}

268 Using ASCAT and QuikSCAT data lead to estimate accurate time means and variabilities of 269surface winds over the coastal and offshore regions around Brittany. Furthermore, as shown above, 270the results may be extended to some near shore locations. Seasonal mean wind speed and direction 271patterns, estimated from the two scatterometers for winter (December-January-February (DFJ)), 272spring (March-April-May (MAM)), summer (June-July-August (JJA)), and fall (September273October-November (SON)), over 12 years (December 1999 through December 2012) are shown in 274Figure 5. The seasonal spatial distributions (not shown) of sampling length (number of retrievals 275falling within a $0.125^{\circ} \times 0.125^{\circ}$ grid point during the study period) are similar to those shown in 276Figure 1. The lowest sampling length values are found during winter and fall, the result of 277eliminating rain impacted data (mainly from QuikSCAT). Overall, however, the seasonal variability 278of the sampling length is quite small. Indeed, on average for offshore (resp. near-shore) grid points 279the numbers of rain-free data are about 1670 (887) in winter and 1870 (968) in summer.

280 Wind speed and direction distributions (Figure 5) correspond to the usual wind patterns for 281the region, with westerly winds prevailing. The patterns are mainly associated to the prevailing 282atmospheric circulation characteristics over Northeast Atlantic Ocean. Offshore wind speeds along 283Brittany coasts exhibit pronounced seasonality, with winter wind speeds almost 50\% higher than 284summer values. The mean wind speed values are about $9 \mathrm{~m} / \mathrm{s}$ and $5.50 \mathrm{~m} / \mathrm{s}$ in winter and summer 285seasons, respectively, over the region. Winter winds are characterized by larger vertical shear and 286smaller interstability shear differences whereas in summer, winds tend to be lower due a relaxed 287meridional temperature gradient and a predominantly stable surface layer. The highest winds are 288found around northern coasts, mainly due to the channeling effect of the English channel. The 289spatial variability tends to be low, which is expected from results provided above (section 3). The 290main spatial differences are found between winds occurring in the northern and southern zones of 291Brittany. The highest mean winds are found over north-western areas, with the lowest in the south292east. The time variation, which can be estimated as the STD of the seasonal wind speed time series 293at each grid point, is higher during winter and fall, reaching $4.5 \mathrm{~m} / \mathrm{s}$ offshore, whereas during the 294summer season, STD values do not exceed 3m/s. Similar STD values are found for nearshore grid 295points. 
296 The spatial distributions of remotely-sensed wind directions lead to fairly steady patterns. On 297average, winds occurring offshore are mostly westerly in winter, north-westerly (NW) in spring in 298southern areas, and are south-westerly (SW) in northern, and NW in southern areas during summer 299and fall. However, such mean patterns should be treated with caution, as the time variability of 300seasonal zonal and meridional wind components are high. For instance, the STD of the zonal 301component varies between $5 \mathrm{~m} / \mathrm{s}$ and $8 \mathrm{~m} / \mathrm{s}$ and between $3 \mathrm{~m} / \mathrm{s}$ and $6 \mathrm{~m} / \mathrm{s}$ during winter and summer, 302respectively. To highlight the wind vector variability, the wind direction frequencies are determined 303for two zones located north and south of $48^{\circ} \mathrm{N}$ during winter and summer seasons (Figure 6). Wind 304directions are given in the oceanographic convention (wind blowing towards). Even though the 305 westerlies (wind direction of $270^{\circ} \pm 30^{\circ}$ versus north) are prevailing over the two regions and for the 306 two seasons, they only account for about $14 \%$ and $11 \%$ of occurrences in the northern and southern 307regions during the winter season. The percentages are calculated with respect to the total number of 308data from the particular region and season. The corresponding easterlies account for about $7 \%$ and $3098 \%$, respectively. During the summer, the frequency of westerlies decreases to $11 \%$ in the northern 310area, whereas it increases to $16 \%$ in the southern zone. The easterlies drop to about $4 \%$ in the two 311regions during the summer. Figure 6 also shows that wind speed conditions are wind direction 312dependent, with the highest winds associated with westerlies and occurring particularly during 313winter. For instance, wind speeds in southern and northern areas are above $12 \mathrm{~m} / \mathrm{s}$ for about $5.7 \%$ 314and $4.2 \%$ of the time, respectively. The frequency drops to $1.7 \%$ and $1.2 \%$ for easterly wind 315 conditions. Although the percentage of $10 \mathrm{~m}$ winds higher than $20 \mathrm{~m} / \mathrm{s}$ is quite small (approximately $3160.2 \%$ of total data), they number 14827 and $89 \%$ of such high winds are westerlies, occurring 93\% 317 of the time during winter or fall. Low winds (less than $5 \mathrm{~m} / \mathrm{s}$ ) account for $22 \%$ of all winds, and their 318easterly and westerly distributions (Figure 6) are similar. The number of low winds reaches a 319 minimum during the winter season for $12 \%$ of the time, and a maximum during summer for $36 \%$ of 320the time.

\section{WIND POWER}

322 Previous results allow the determination and analysis of wind power density only estimated 323from scatterometer retrievals. It aims to characterize the resource availability at local scales over 324Brittany region.

\subsection{Determination Method}

326 The distribution of the wind power density $(E)$ over Brittany offshore zone is determined from 327available winds. It may be directly estimated from time series at each grid point, based on the 328following formulae: 


$$
E=\frac{1}{2} \rho \overline{W^{3}}
$$

331(4)where $\rho$ is the air density, assumed to be a constant $1.225 \mathrm{kgm}^{-3}$ (at $10^{\circ} \mathrm{C}$ ), and $W$ is wind speed.

332 Alternatively, E may be estimated based on the wind speed density probability function (pdf), 333using the following relationship:

$$
E=\frac{1}{2} \rho A^{3} \Gamma\left(1+\frac{3}{C}\right)
$$

337where $A$ and $C$ are the parameters of the Weibull pdf [16] and $\Gamma$ denotes the Gamma function.

338 The Weibull pdf of wind speed ( $\mathrm{W}$ in $\mathrm{m} / \mathrm{s}$ ) is expressed as:

339

$$
P(W ; A, C)=(C / A)(W / A)^{C-1} \exp \left(-(W / A)^{C}\right)
$$

$342 A$ is a scaling parameter expressed in $\mathrm{m} / \mathrm{s}$, and $C$ is a dimensionless shape parameter.

$343 \quad P$ indicates the probability of wind speed occurrence.

344 Several methods exist to estimate Weibull parameters $A$ and $C$ [17] which provide quite 345similar results. For instance the method of moment yields the estimation of the mean $(\mu)$ and the 346variance $\left(\sigma^{2}\right)$ of Weibull distribution as a function of the Weibull parameters

$$
\mu=A \Gamma(1 / C+1) \text { and } \sigma^{2}=A^{2}\left(\Gamma(2 / C+1)-\Gamma^{2}(1 / C+1)\right)
$$

$350 \quad$ Using the above equations the Weibull parameters are determined as:

$352 C=(\sigma / \mu)^{-1.086}$ and $A=\mu / \Gamma(1 / C+1)$

354 The Weibull parameters are estimated at each grid cell and from the available time series. 355Spatial distribution of the scale parameter A is very similar to that of mean wind speed (not shown). 356Its values are mainly between $7.4 \mathrm{~m} / \mathrm{s}$ and $9 \mathrm{~m} / \mathrm{s}$. The lowest values are located near coasts, while the 357highest are off coast and along English Channel. Spatial distribution of sharp parameter C exhibits 358 more variability. Indeed, the highest values, about of 2.6, are mostly found in north zone related to 359narrower wind speed distributions, while the lowest of 2.2 are depicted in south of Brittany region 360where dominant peak is not well defined as shown in Figure 6.

361 To assess the accuracy of the Weibull fitting method, the mean and standard deviation of the 362empirical distribution (determined from observations) is compared to those estimated from the 363predicted distribution (eq. 4). Comparisons are performed for each grid cell using the Student's t- 
364test. The main results (not shown) indicate that the empirical and predicted statistical means are 365comparable at the 95\% confident level. Similar results are found for standard deviations 366comparisons.

367 The Weibull pdf also provides an estimation of the most probable wind speed (eq (7)) and the 368wind speed generating maximum energy (eq (8)):

$$
W_{m p}=A\left(1-\frac{1}{C}\right)^{\frac{1}{C}}
$$

$$
W_{\max }=A\left(1+\frac{2}{C}\right)^{\frac{1}{C}}
$$

371 The analysis of $W_{m p}$ (eq. 7) and $W_{\max }$ (eq. 8), calculated for each year at each grid cell, 372indicates that both have significant spatial and temporal variabilities. In the north, minimum 373nearshore and offshore values of $W_{m p}$ are about $5.5 \mathrm{~m} / \mathrm{s}$ and $7.5 \mathrm{~m} / \mathrm{s}$, respectively. In the south, except 374at some specific locations, minimum values do not exceed $5.5 \mathrm{~m} / \mathrm{s}$. $W_{m p}$ maximum values fall within $37510 \mathrm{~m} / \mathrm{s}$ and $11.5 \mathrm{~m} / \mathrm{s}$ in the north, and within $7 \mathrm{~m} / \mathrm{s}$ and $10 \mathrm{~m} / \mathrm{s}$ in the south.

376 The minimum values of $W_{\max }$ mostly range between $9 \mathrm{~m} / \mathrm{s}$ and $11 \mathrm{~m} / \mathrm{s}$ moving from nearshore 377to offshore. A large variation is seen south of Brittany where $W_{\max }$ minimum and maximum values 378are about $9.5 \mathrm{~m} / \mathrm{s}$ and $16 \mathrm{~m} / \mathrm{s}$, respectively. The latter is associated with a storm which occurred on 379December, $26^{\text {th }} 1999$.No significant trend for the period $1999-2012$ is found for either $W_{m p}$ or $380 W_{\max }$.

\subsection{Height Issue}

382 Scatterometer retrievals are available at 10m height as equivalent neutral winds (ENWs). The 383overall difference between ENW and "real" (including stratification impact) winds is about $3840.20 \mathrm{~m} / \mathrm{s}$. Better determination and characterization of wind energy estimated from scatterometer 385 observations requires calculations at hub height. The latter generally range between $50 \mathrm{~m}$ and $100 \mathrm{~m}$ 386above the surface of the water. Therefore, the local shear component is required to accurately 387estimate the winds at the height of the hub from the 10m ENW scatterometer winds.

388 In the atmospheric surface boundary layer (SBL), similarity theory yields the logarithmic 389wind speed profile at height z (e.g. [13]):

$$
W(z)=\frac{W}{k}\left(\ln \left(\frac{Z}{z_{0}}\right)-\Psi\left(\frac{Z}{L}\right)\right)
$$


391 Where $\mathrm{W}_{*}$ is the friction velocity, $\mathrm{k}$ the von Kármán constant (generally taken to be 0.4 ), $\mathrm{z}_{0}$ is 392the aerodynamic roughness length and the stability, $\Psi$, is a function of $\mathrm{z} / \mathrm{L}$, where $\mathrm{L}$ is known as the 393Monin-Obukhov lengthscale. For a neutral boundary layer $\Psi\left(\frac{Z}{L}=1\right)=0$, the wind profile is :

$$
W(z)=\frac{W}{k} \ln \left(\frac{z}{z_{0}}\right)
$$

395 The calculation of W(z) from (eq. 9) or from (eq. 10) is not straightforward and requires an 396iterative procedure (e.g. [13]). Furthermore, in addition to the $10 \mathrm{~m}$ scatterometer winds, bulk vari397ables such as sea surface temperature (SST), air temperature (AT) and relative humidity (RH) are 398also needed. These are obtained from the National Centers for Environmental Prediction (NCEP) 399Climate Forecast System Reanalysis (CFSR) [18]. They are available over global ocean with a spa400tial resolution of about 38km. Only CFSR SST, AT and RH available at synoptic times 00h:00, 40106h:00, 12h:00, and 18h:00 UTC are used in this study. They are interpolated in space and time 402over ASCAT and QuikSCAT swaths using a bilinear method.

403 In this study only the winds at a height of $100 \mathrm{~m}$ are estimated using the COARE3.0 model $404[5]$.

\subsection{Spatial and temporal Characteristics}

406 In previous sections, we clearly showed that scatterometer retrievals are accurate sources of 407wind information and thus a valuable resource to characterize geographical and temporal patterns of 408offshore wind energy along the coasts of Brittany. The spatial distributions of wind power density $\mathrm{E}$ 409determined from (eq. 5) based on 10m winds are shown in Figure 7 for four seasons. As expected, 410the spatial distributions have similar patterns to those obtained for winds (Figure 5). The highest 411and lowest values match high and low wind conditions. In winter, 95\% of E values fall within 550 $412 \mathrm{~W} / \mathrm{m}^{2}$ and $850 \mathrm{~W} / \mathrm{m}^{2}$, whereas in summer this range is drastically reduced to $190 \mathrm{~W} / \mathrm{m}^{2}$ and $413340 \mathrm{~W} / \mathrm{m}^{2}$. The E values estimated at $100 \mathrm{~m}$ height fall within $1200 \mathrm{~W} / \mathrm{m}^{2}$ and $1900 \mathrm{~W} / \mathrm{m}^{2}$ in winter 414and within $370 \mathrm{~W} / \mathrm{m}^{2}$ and $650 \mathrm{~W} / \mathrm{m}^{2}$ in summer. Seasonal variations are more pronounced in certain 415areas. For instance, there is a factor of 4.5 between winter and summer $E$ values estimated over the 416 “Côtes d'Armor” offshore region located north of Brittany. Similar results are obtained for E 417estimated at $100 \mathrm{~m}$ height.

418 The above results are calculated from all available valid scatterometer winds. To provide 419practical estimations of wind power density E, calculations are usually only performed for $10 \mathrm{~m}$ 420wind speeds ranging between a minimum of $4 \mathrm{~m} / \mathrm{s}$, called the cut-in, and a maximum of $25 \mathrm{~m} / \mathrm{s}$, 421called the cut-off. We assume that for winds lower than the cut-in, not enough energy is available 
422from the wind to allow for power production. For winds exceeding cut-off, the turbines would be 423shut down for self-protection.

424 Discrete and modeled (eq. 6) wind distributions are used to determine the percentage of winds 425occurring between the cut-in and cut-off limits. Both methods provide very close results. They 426indicate that winds are expected to fall within these limits nearly $86 \%$ of time. However this 427percentage has significant spatial and temporal variability. For instance, in the winter it increases to $42893 \%$, and in the summer it decreases to $79 \%$. The related spatial distribution indicates that at near429shore locations, the percentages are slightly lower than those estimated at regional scale. They 430account for approximately 85\%, 80\%, 70\%, and 82\% during winter, spring, summer, and fall, 431respectively.

432 To further assess the temporal variability of E estimated at near-shore grid cells (i.e. where the 433distance to the shore is less than $50 \mathrm{~km}$ ), inter-annual and intra-annual time series are calculated for 434the period January 2000 - December 2012. For the spatial variability of E (Figure 7), intra- and 435inter-annual series are calculated for two near-shore zones located north (north Brittany) and south 436of $48^{\circ}$ N28' (south Brittany). To minimize the impact of biases related to differences in sampling 437length and to local effects of atmosphere and ocean on winds and thus on wind power energy, the 438time series are normalized by long-term averages as follows:

$439 \quad E^{\prime}=\frac{\overline{E_{m}}}{\bar{E}}$ and $E^{\prime \prime}=\frac{\overline{E_{y}}}{\bar{E}}$

$440 \quad$ E' and E" are intra-annual and inter annual E series.

$441 \quad \overline{E_{m}}$ (m is month number) indicates monthly averaged $\mathrm{E}$ calculated for each calendar month 442of the study period.

$443 \overline{E_{y}}$ is yearly averaged E calculated for each year of the study period.

$444 \bar{E}$ is E mean value calculated from all selected data.

445 Time series of E' (Figure 8a) and E" (Figure 8b) are shown in red for north and blue for 446south Brittany.

447 In the two zones E' shows strong seasonal variations. The highest E' values are found during 448winter for both regions. More specifically, E' maximum values are found in December in the south, 449while in the north, maximum values found in December and January are very close. Minimum 450values in the zones are mainly found in June. Winter and summer intra-annual values differ by a 451factor greater than 3. Although E' estimated for north and south Brittany are similar, the maximum 452values occur with a shift of one month, in January and December, respectively.

453 The inter-annual variability (Figure 8b) indicates significant year to year variability. The 454impact of data sources on such variability is evident. Indeed, the lowest E" estimates are found for 455the period 2010-2012 where wind retrievals are mainly from the ASCAT coastal retrievals 
456(ASCAT_coast). The latter include coastal wind information that would be lower than offshore 457winds. The highest E" values are found for 2002 and 2007 in both northern and southern areas, 458whereas the lowest wind power energies occur in 2005 and 2011. Note that the low winds which 459occur in 2010 are mostly in the southern zone. As expected from equation (5), these extreme E" 460values are related to wind conditions. For instance, in 2002 high winds exceeding $24 \mathrm{~m} / \mathrm{s}$ occurred in 461February. The number of days when retrieved winds exceeded $16 \mathrm{~m} / \mathrm{s}$ is 22 . Low E" values found 462during 2005 are mainly associated with low winds which occurred in November and December.

463

\section{CONCLUSION}

465 Precise and accurate wind speeds and directions with high space and temporal resolutions are 466required for marine renewable energy (MRE) investigations. It is quite common to use in-situ data 467provided by meteorological centres or by research organisations as wind references. Indeed, their 468operational maintenance regimes and their technical and scientific validations ensure their accuracy. 469Furthermore, they provide winds with high temporal resolution. However, their spatial distribution 470cannot meet the MRE requirements. In the present study, remotely-sensed data derived from 471ASCAT and QuikSCAT scatterometers are used to assess the spatial and temporal wind and power 472energy characteristics along the coasts of Brittany during the period spanning December 1999 473through December 2012. Selecting only valid retrievals based upon data quality flags, the sampling 474lengths of wind observations at each grid cell of $0.125^{\circ} \times 0.125^{\circ}$ are within 500 (near coast cells) and 4756000 (off coasts cells). Such sampling lengths exceed the requirements for wind observations as 476described by Barthelmie et al [19]. They concluded that 150 observations are needed to characterize 477the mean and the variance of wind speed.

478 The topic of this study is not the validation of scatterometer retrievals, however, several 479papers have investigated previously the accuracy of ASCAT and QuikSCAT wind speed and 480direction (e.g. [4]). This study shows that scatterometer winds are in good agreement with 481meteorological station data in this region. For near-shore stations, the correlation between in-situ 482and scatterometer wind speed exceeds 0.80 , which indicates the coherency of the two observation 483methods.

484 The sampling length of the scatterometer observations and the comparisons of in-situ data and 485retrievals presented here show that remotely-sensed data can be used to accurately characterize the 486wind speed distributions and thus the associated wind power energy at regional scales. However, 487the main limitation of scatterometer data for wind and energy distribution studies is related to the 488radar sampling which depends on the satellite orbit characteristics. As both ASCAT and QuikSCAT 489data are mainly available in the morning and evening, the data may not adequately resolve the 
490diurnal cycle. The impact of errors due to the scatterometer sampling schemes is investigated using 491comparisons between wind distribution parameters estimated for each station from all valid in-situ 492data and from in-situ data occurring close to scatterometer overpasses. The findings show that the 493sampling error has a small impact on the distribution results. In fact, the two estimations of the 494distribution parameters are comparable at a confidence level of 95\%. The second main limitation of 495remotely-sensed winds is that the retrievals are given as equivalent neutral winds (ENW) at $10 \mathrm{~m}$ 496height. No vertical wind profile is available from scatterometer measurements. To circumvent this 497limitation, the estimation of wind at hub height $(50 \mathrm{~m}-100 \mathrm{~m})$ is performed using the COARE3.0 498parameterization [5]. The required bulk variables are $10 \mathrm{~m}$ winds from scatterometers, $10 \mathrm{~m}$ air 499temperature, 10m specific air humidity, and sea surface temperature which were obtained from 500CFSR re-analyses.

501 The analysis methods summarized above enable the characterisations of winds and the related 502wind power around the coasts of Brittany coasts. The highest and lowest wind conditions are found 503over the north-west and south-east zones, respectively. For instance, the maximum values of the $504 \mathrm{most}$ probable wind speed are within $10 \mathrm{~m} / \mathrm{s}$ and $11.5 \mathrm{~m} / \mathrm{s}$ in the north, whereas in the south they are 505within $7 \mathrm{~m} / \mathrm{s}$ and $10 \mathrm{~m} / \mathrm{s}$. Although the prevailing winds are westerly, wind directions exhibit high 506variability. Indeed, during winter season westerlies account only for $14 \%$ and $11 \%$ in north and 507south areas, respectively. For wind power evaluation purpose, the use of scatterometer winds 508indicate that on average $86 \%$ of data are within the cut-in and cut-off limits. However, this 509percentage has significant spatial and temporal variation. As expected, the wind power exhibits 510similar patterns to wind speed. For instance, the highest and lowest values are found in winter and 511summer, respectively. However, the seasonal variation is more pronounced at specific locations, 512such as Côtes d'Armor.

513 This study highlights the usefulness of the long time series of remotely-sensed winds for the 514evaluation and the analysis purposes of wind power off Brittany coasts. Further improvements are 515expected through the combination of scatterometer, in-situ, and regional numerical model data to 516investigate finer space and time wind scales and their impact on energy resource potential.

\section{Acknowledgement}

518We are grateful to JPL, EumetSat, KNMI, Météo-France, Cersat/Ifremer for providing valuable 519remotely sensed and in-situ data used in this study. We thank Dr Jenny Hanafin for her very helpful 520comments on the manuscript. 


\section{References}

522

523[1] Sanchez R., P. Relvas, H. O. Pires, 2007: Comparisons of ocean scatterometer and anemometer

524 winds off the southwestern Iberian Peninsula. Continental Shelf Research, Vol. 27, Issue 2,

525 pp 155-175. doi:10.1016/j.csr.2006.09.007

526[2]_Pimenta F., W. Kempton, R. Garvine, 2008: Combining meteorological stations and satellite 527 data to evaluate the offshore wind power resource of Southeastern Brazil, Renewable Energy, $528 \quad 33$, pp. 2375-2387. doi:10.1016/j.renene.2008.01.012

529[3]_Karagali, I., A. Peña,, M. Badger, C. B. Hasager, 2012: Wind characteristics in the North and 530 Baltic Seas from the QuikSCAT satellite. Wind Energy. doi: 10.1002/we.1565

531[4]_Bentamy, A., S. A. Grodsky, J. A. Carton, D. Croizé-Fillon, And B. Chapron, 2012: 532 MATCHING ASCAT AND QUIKSCAT WINDS, J. GEOPH. RES., 117, C02011, 533 DOI:10.1029/2011JC007479.

534 [5] Portabella, M., A. Stoffelen, W. Lin, A. Turiel, A. Verhoef, J. Verspeek and J. Ballabrera-Poy, 535 2012: Rain Effects on ASCAT-Retrieved Winds: Toward an Improved Quality Control IEEE 536 Transactions on Geoscience and Remote Sensing, 50, 7, 2495- 2506, 537 doi:10.1109/TGRS.2012.2185933.

538[6]_Fore A., B. Stiles, R. S. Dunbar, B. Williams, A. Chau, L. Ricciardulli, F. Wentz, T. Meissner 539 and E. Rodridguez, 2011: Point-wise wind retrieval and ambiguity removal improvements for 540 the QuikSCAT climatological data set. International Ocean Vector Wind Science Team 541 Meeting Annapolis, Maryland, USA, 9-11 2011

542 (http://coaps.fsu.edu/scatterometry/meeting/past.php\#2011)

543[7] Ricciardulli L. and F. Wentz, 2011: Reprocessed QuikSCAT (V04) wind vectors with Ku-2011 544 geophysical model function. Remote Sensing Systems Technical Report 043011 545 (http://www.ssmi.com/qscat/qscat Ku2011 tech report.pdf)

546[8] Bentamy, A., D. Croize-Fillon, and C. Perigaud , 2008: Characterization of ASCAT 547 measurements based on buoy and QuikSCAT wind vector observations, Ocean Sci., 4, 265$548 \quad 274$.

549[9] Verspeek, J.; A. Stoffelen, M, Portabella, H. Bonekamp, C. Anderson, and J.F. Saldana (2010), 550 Validation and Calibration of ASCAT Using CMOD5.n, IEEE Transactions on Geoscience 551 and Remote Sensing, 48, 386-395, doi: 10.1109/TGRS.2009.2027896 
553[10] Verhoef, A., M. Portabella and A. Stoffelen, High-resolution ASCAT scatterometer winds near

554 the coast. IEEE Transactions on Geoscience and Remote Sensing, 2012, 50, 7, 2481555 2487, doi:10.1109/TGRS.2011.2175001.

556[11] Grodsky, S. A., V. N. Kudryavtsev, A. Bentamy, J. A. Carton, and B. Chapron , 2012: Does 557 direct impact of SST on short wind waves matter for scatterometry?, Geophys. Res. Lett., 39, 558 L12602, DOI: 10.1029/2012GL052091.

559[12] Jet Propulsion Laboratory (JPL), 2006: QuikSCAT Science Data Product User's Manual 560 Overview \& $\quad$ Geophysical Data $\quad$ Products, $1 /$ podaac561 ftp.jpl.nasa.gov/allData/quikscat/L2B/docs/QSUG v3.pdf

562[13__Fairall, C.W., E.F. Bradley, J.E. Hare, A.A. Grachev, and J.B. Edson (2003), Bulk 563 Parameterization of Air-Sea Fluxes: Updates and Verification for the COARE Algorithm, J. 564 Clim., 16, 571-591.

565[14] Crosby, D.S., L.C. Breaker,and W.H. Gemmill, 1993: A proposed definition for vector 566 correlation in geophysics: theory and application. Journal of Atmospheric and Oceanic 567 Technology, 10, 355 - 367.

568 [15]_Hsu S. A., 1981: Models for estimating offshore winds from onshore meteorological 569 measurements, Boundary Layer Meterology, Volume 20, Issue 3, pp 341-351

570 [16] Justus C.G., Hargraves W.R., Yalcin A. , 1976: Nationwide assessment of potential output 571 from windpowered generators. Journal of Applied Meteorology, Vol. 15, pp 673-678. 572 doi:10.1175/1520-0450(1976)015<0673:NAOPOF>2.0.CO;2

573 [17] Pavia E.G., O’Brien J.J. (1986). Weibull statistics of wind speed over the ocean. J. Climate 574 Appl. $\quad$ Meteor., 25, pp 1324-1332. doi:10.1175/1520575 0450(1986)025<1324:WSOWSO>2.0.CO;2

576[18] Saha S., and Coauthors, 2010: The NCEP Climate Forecast System Reanalysis. Bull. Amer. 577 Meteor. Soc., 91, 1015-1057. doi: http://dx.doi.org/10.1175/2010BAMS3001.1

578[19] Barthelmie R J, Pryor S., 2003: Can satellite sampling of offshore wind speeds realistically 579 represent wind speed distributions? Journal of Applied Meteorology 42(1) 


\section{Tables}

Table 1 : Meteorological station Id and coordinates.

\begin{tabular}{|c|c|c|c|}
\hline WMO Id & Name & Latitude & Longitude \\
\hline 07207 & Belle Ile & $47^{\circ} 17^{\prime} 41^{\prime \prime} \mathrm{N}$ & $3^{\circ} 13^{\prime} 6^{\prime \prime} \quad \mathrm{W}$ \\
\hline 07107 & Brignogan & $48^{\circ} 40^{\prime} 35^{\prime \prime} \mathrm{N}$ & $4^{\circ} 19^{\prime} 52^{\prime \prime} \mathrm{W}$ \\
\hline 07116 & Ile de Batz & $48^{\circ} 45^{\prime} 0^{\prime \prime} \quad \mathrm{N}$ & $4^{\circ} 1^{\prime} 0^{\prime \prime}$ \\
\hline 07203 & Ile de Groix & $47^{\circ} 39^{\prime} 8 " \quad \mathrm{~N}$ & $3^{\circ} 30^{\prime} 8^{\prime \prime} \quad W$ \\
\hline 03895 & Jersey & $49^{\circ} 12^{\prime} 35^{\prime \prime} \mathrm{N}$ & $2^{\circ} 11^{\prime} 39^{\prime \prime} \mathrm{W}$ \\
\hline 07109 & Lanvéoc & $48^{\circ} 17^{\prime} 0^{\prime \prime} \quad \mathrm{N}$ & $4^{\circ} 26^{\prime} 0^{\prime \prime} \quad W$ \\
\hline 07100 & Ouessant & $48^{\circ} 28^{\prime} 24^{\prime \prime} \mathrm{N}$ & $5^{\circ} 3 ' 25^{\prime \prime} \quad W$ \\
\hline 07117 & Ploumanac'h & $48^{\circ} 49^{\prime} 33^{\prime \prime} \mathrm{N}$ & $3^{\circ} 28^{\prime} 23^{\prime \prime} \mathrm{W}$ \\
\hline 07200 & Penmarc'h & $47^{\circ} 47^{\prime} 51^{\prime \prime} \mathrm{N}$ & $4^{\circ} 22^{\prime} 29^{\prime \prime} \mathrm{W}$ \\
\hline 07103 & Pointe du Raz & $48^{\circ} 2^{\prime} 20^{\prime \prime} \quad \mathrm{N}$ & $4^{\circ} 43^{\prime} 55^{\prime \prime} \mathrm{W}$ \\
\hline 07216 & Saint Nazaire & $47^{\circ} 14^{\prime} 2^{\prime \prime} \quad \mathrm{N}$ & $2^{\circ} 17^{\prime} 55^{\prime \prime} \mathrm{W}$ \\
\hline
\end{tabular}

Table 2: Statistics of differences between meteorological station and scatterometer wind speeds during the 2008 - 2012 period. bs and $\rho$ are symmetrical regression coefficient and correlation coefficient, respectively.

\begin{tabular}{|c|c|c|c|c|c|}
\hline Station & Length & Bias & STD & bs & $\rho$ \\
\hline All & 92170 & -0.81 & 2.21 & 0.95 & 0.83 \\
\hline 07207 & 16630 & -1.06 & 1.59 & 1.05 & 0.86 \\
\hline 07107 & 5206 & -1.53 & 1.82 & 1.07 & 0.82 \\
\hline 07116 & 1443 & -0.54 & 2.44 & 0.84 & 0.76 \\
\hline 07203 & 6919 & -0.44 & 1.36 & 0.97 & 0.87 \\
\hline 03895 & 18125 & -1.68 & 1.76 & 1.12 & 0.84 \\
\hline 07100 & 18471 & 0.07 & 1.66 & 0.93 & 0.89 \\
\hline 07117 & 4631 & -2.39 & 1.60 & 1.37 & 0.84 \\
\hline 07200 & 9421 & -0.61 & 1.80 & 0.91 & 0.84 \\
\hline 07103 & 9251 & 0.49 & 2.07 & 0.78 & 0.86 \\
\hline 07216 & 2071 & -1.78 & 2.32 & 0.73 & 0.75 \\
\hline
\end{tabular}

Table 3: Statistical parameters calculated for each station, for all data (top row) and for selected (within one hour of scatterometer overpasses) data (bottom row).

\begin{tabular}{|c|c|c|c|c|c|c|c|c|c|}
\hline Station & Length & Mean & Median & STD & Skew & Kur & $\mathrm{P}_{10}$ & $\mathrm{P}_{90}$ & $\mathrm{P}_{95}$ \\
\hline \multirow{2}{*}{07207} & 37288 & 6.01 & 5.61 & 3.06 & 0.93 & 4.28 & 2.58 & 10.00 & 11.81 \\
\cline { 2 - 11 } & 8994 & 5.91 & 5.50 & 2.96 & 0.86 & 4.07 & 2.50 & 9.81 & 11.31 \\
\hline \multirow{2}{*}{07107} & 35992 & 5.95 & 5.31 & 3.29 & 0.96 & 3.96 & 2.31 & 10.50 & 12.30 \\
\hline
\end{tabular}




\begin{tabular}{|c|c|c|c|c|c|c|c|c|c|}
\hline & 4533 & 5.79 & 5.19 & 3.22 & 0.86 & 3.58 & 2.11 & 10.31 & 12.18 \\
\hline \multirow{3}{*}{07116} & 7886 & 6.51 & 6.17 & 3.48 & 1.26 & 7.81 & 2.61 & 11.30 & 12.89 \\
\cline { 2 - 10 } & 768 & 6.41 & 5.93 & 3.67 & 2.05 & 14.45 & 2.61 & 10.81 & 12.31 \\
\hline \multirow{2}{*}{07203} & 34184 & 6.63 & 6.19 & 3.25 & 0.76 & 3.74 & 2.89 & 11.00 & 12.61 \\
\cline { 2 - 10 } & 3246 & 6.59 & 6.19 & 3.28 & 0.74 & 3.71 & 2.69 & 10.89 & 12.61 \\
\hline \multirow{2}{*}{03895} & 59638 & 5.79 & 5.67 & 2.67 & 0.86 & 5.07 & 2.58 & 9.25 & 10.81 \\
\cline { 2 - 10 } & 6461 & 5.90 & 5.67 & 2.79 & 0.78 & 3.95 & 2.58 & 9.78 & 10.81 \\
\hline \multirow{2}{*}{07100} & 36009 & 7.47 & 7.00 & 3.62 & 0.69 & 3.43 & 3.11 & 12.33 & 14.11 \\
\cline { 2 - 10 } & 8699 & 7.38 & 6.89 & 3.53 & 0.69 & 3.62 & 3.11 & 12.19 & 13.69 \\
\hline \multirow{2}{*}{07117} & 36914 & 5.15 & 4.64 & 2.66 & 0.88 & 3.77 & 2.11 & 8.75 & 10.31 \\
\cline { 2 - 10 } & 3664 & 5.03 & 4.69 & 2.49 & 0.83 & 4.03 & 2.11 & 8.31 & 9.53 \\
\hline \multirow{2}{*}{07200} & 36406 & 6.37 & 5.61 & 3.65 & 1.01 & 3.95 & 2.39 & 11.50 & 13.50 \\
\cline { 2 - 10 } & 6522 & 6.24 & 5.50 & 3.53 & 1.06 & 4.24 & 2.50 & 11.11 & 13.00 \\
\hline \multirow{2}{*}{07103} & 36096 & 7.60 & 7.00 & 4.19 & 0.80 & 3.56 & 2.61 & 13.36 & 15.40 \\
\cline { 2 - 9 } & 5145 & 7.47 & 6.89 & 4.10 & 0.83 & 3.86 & 2.61 & 13.00 & 14.89 \\
\hline \multirow{2}{*}{07216} & 33951 & 5.89 & 5.11 & 3.56 & 1.38 & 5.77 & 2.11 & 10.80 & 12.89 \\
\cline { 2 - 9 } & 3274 & 5.89 & 5.00 & 3.81 & 1.48 & 5.95 & 2.11 & 11.19 & 13.39 \\
\hline
\end{tabular}

592

593 


\section{Figure captions}

600

601 - Figure 1: Sampling length of ASCAT and QuikSCAT valid retrievals occurring during the $602 \quad$ period : October 1999 - October 2012.

603 - Figure 2 : Meteorological station locations shown as cross symbols

604 - Figure 3: Spatial correlation between meteorological station and scatterometer 10m wind 605 speeds as a function of distance separating the two source locations..

606 - Figure 4: Comparisons of collocated meteorological station and scatterometer wind speeds.

607 Figure4a illustrates the results obtained for all collocated data, while Figure4b is for the 608 satellite data collocated with the station at Ouessant.

609 - Figure 5: Seasonal mean wind speed (in color) and wind direction (arrows) estimated from 610 scatterometer retrievals during the period January 2000 - December 2012

611 - Figure 6: Wind roses derived from scatterometer retrievals during the period January 2000 612 - December 2012. Figure 6a and 6b indicate the results obtained from data occurring north 613 of $40^{\circ} \mathrm{N}$ for winter and summer seasons, respectively. Figure $6 \mathrm{c}$ and $6 \mathrm{~d}$ illustrate similar 614 results for data occurring south of $48^{\circ} \mathrm{N}$

615 - Figure 7: Seasonal mean wind power (in color) estimated from scatterometer retrieval 616 distributions during the period January 2000 - December 2012

617 - Figure 8: Intra-annual (Figure 8a) and inter-annual (Figure 8b) of wind power estimated 618 from scatterometer retrieval distributions during the period January 2000 - December 2012 619 
625

626

627

628

629

630

631

632

633

634

635

636

637

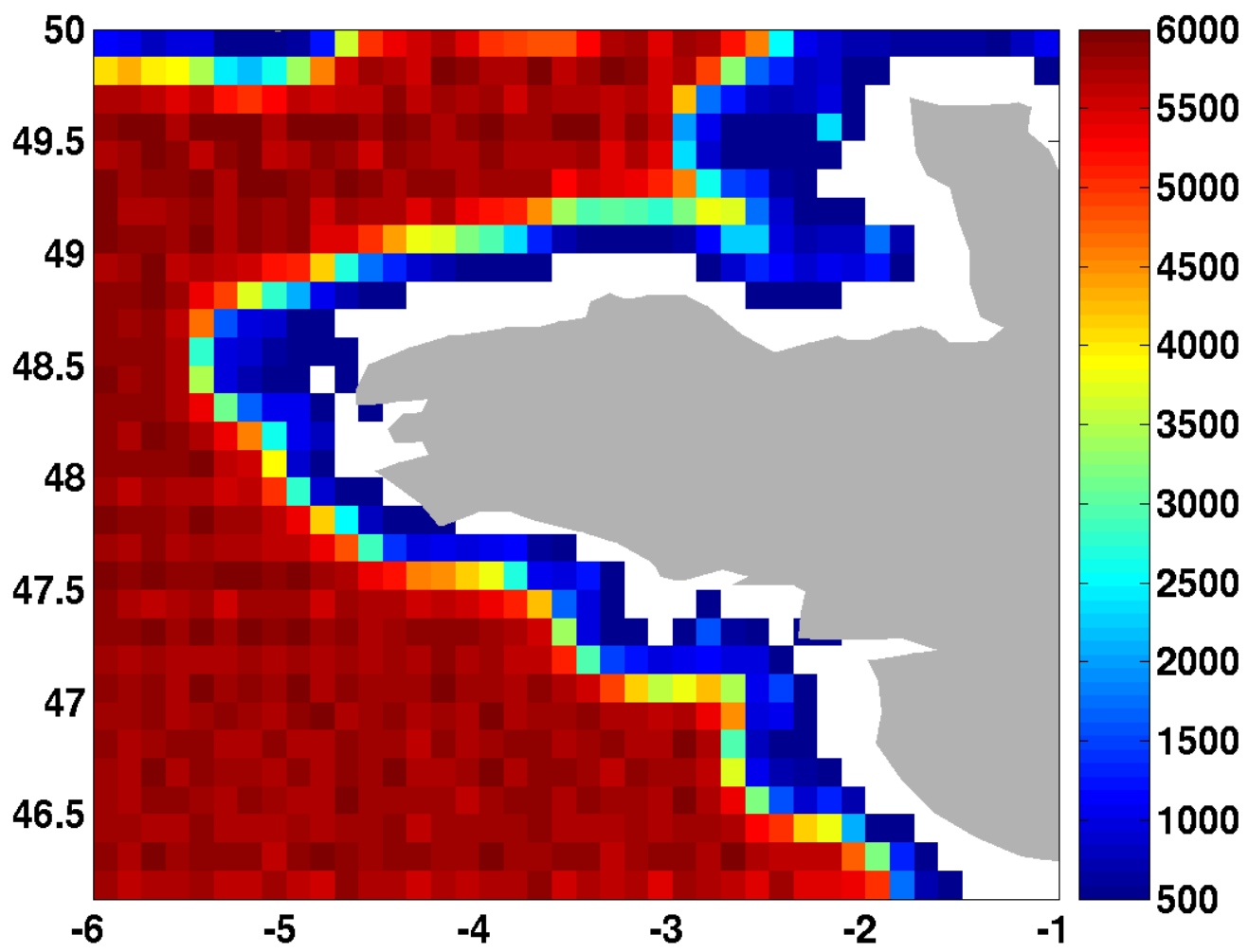

Figure 1: Sampling length of ASCAT and QuikSCAT valid retrievals occurring during the period : October 1999 - October 2012. 


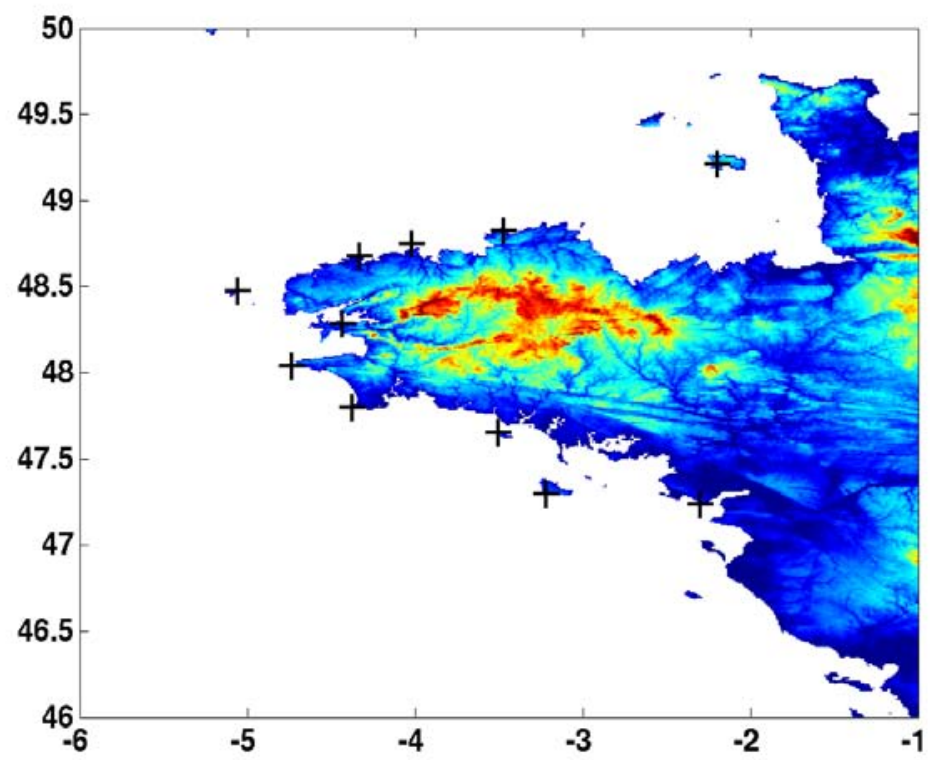

Figure 2 : Meteorological station locations shown as cross symbols 


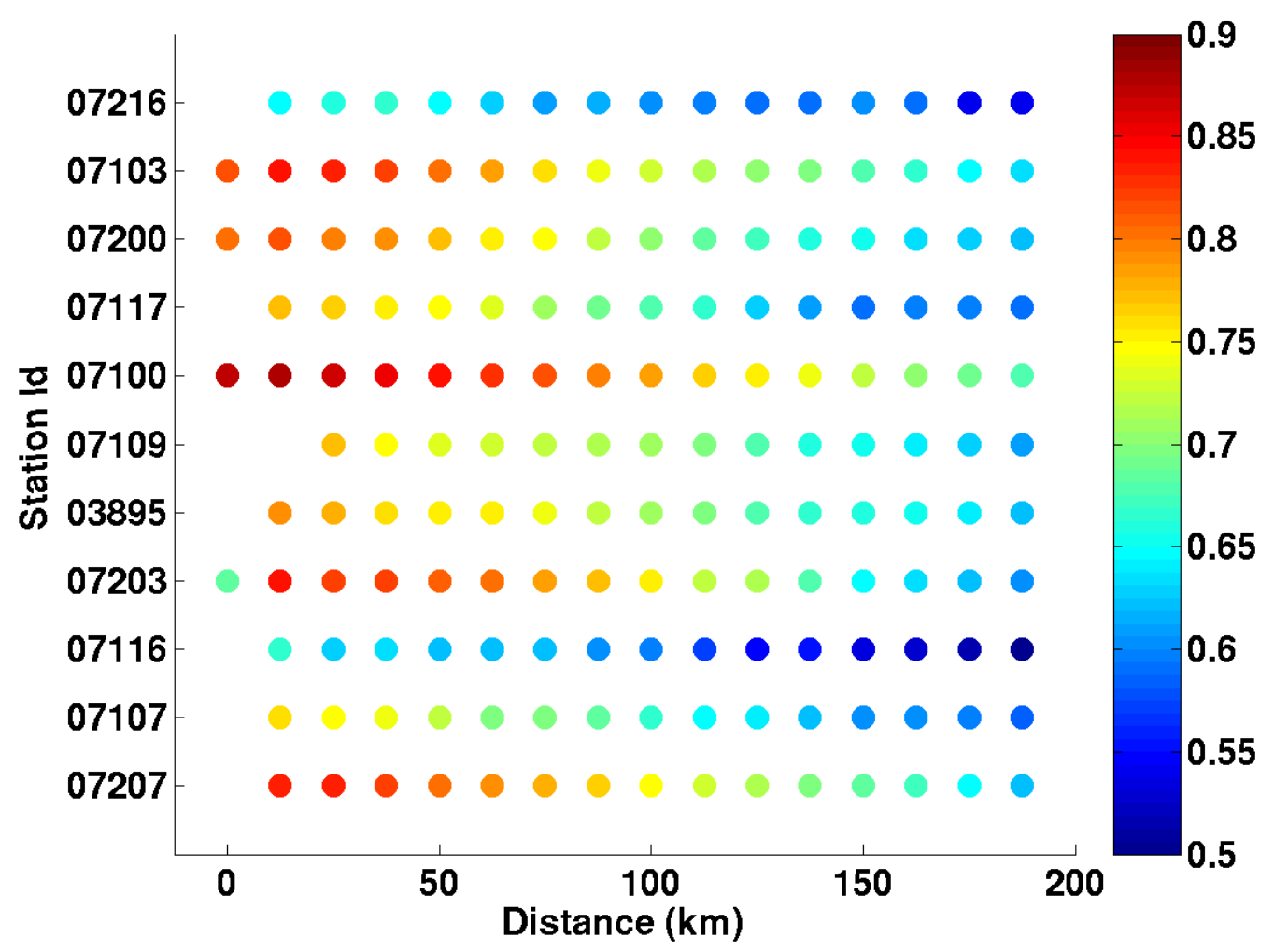

Figure 3: Spatial correlation between meteorological station and scatterometer $10 \mathrm{~m}$ wind speeds as a function of distance separating the two source locations.. 

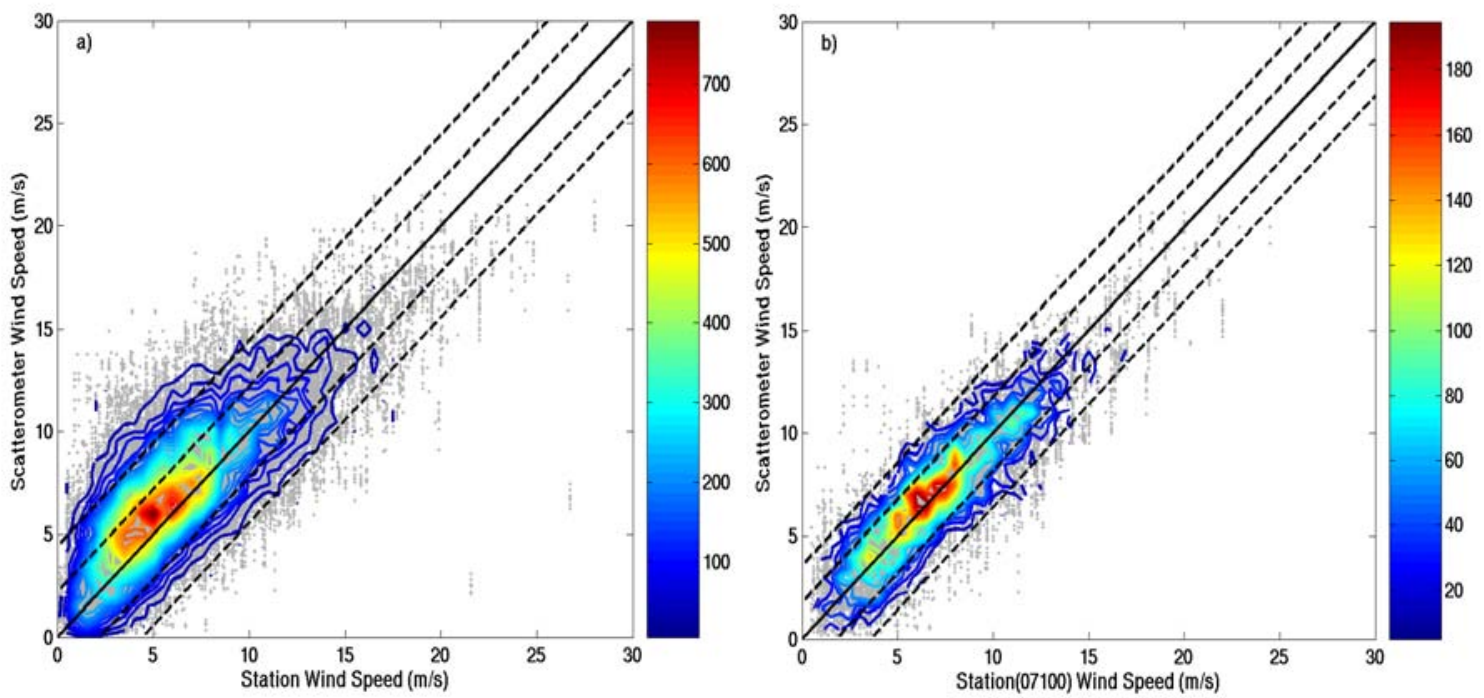

726.igure 4: Comparisons of collocated meteorological station and scatterometer wind speeds. Figure4a 7idglustrates the results obtained for all collocated data, while Figure4b is for Ouessant station and $72 g$ tellite rollnrated data

730

731 

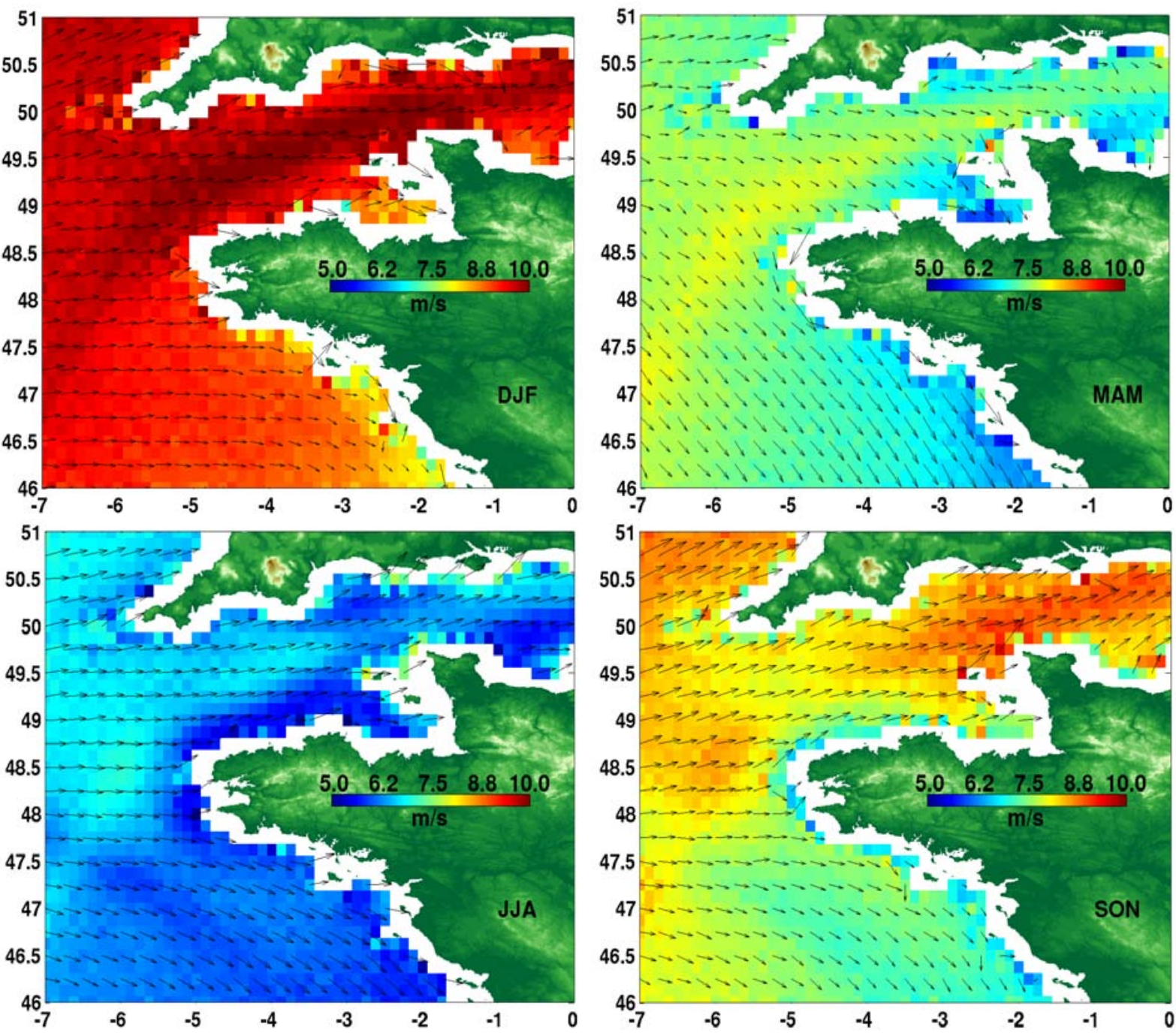

769 igure 5: Seasonal mean wind speed (in color) and wind direction (arrows) estimated from scatterometer $7 f$ ftrievals during the period January 2000 - December 2012

771

772

773

774

775

776

777

778

779

780

781

782

783

784

785

786

787

788

789 
a) North $48 \mathrm{~N}$ Winter

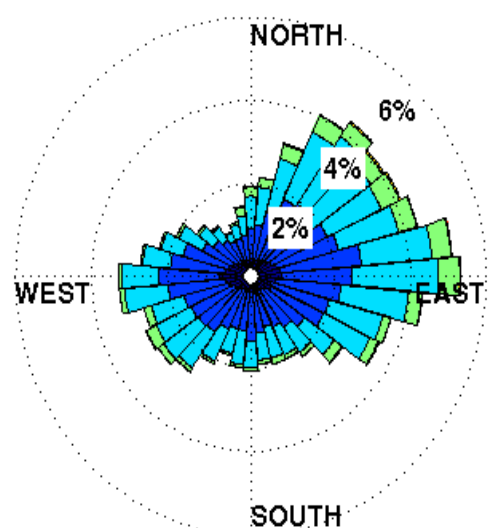

c) North $48 \mathrm{~N}$ Summer

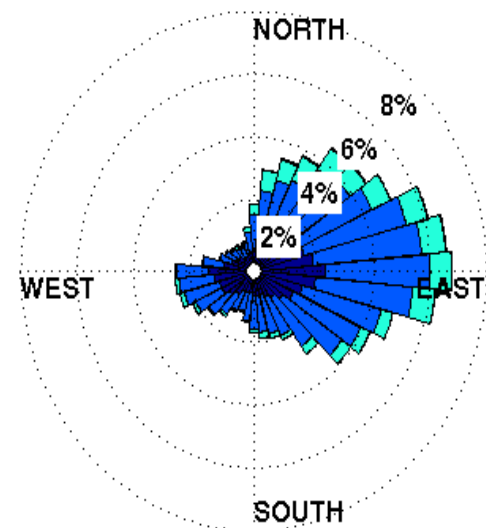

b) South $48 \mathrm{~N}$ Winter

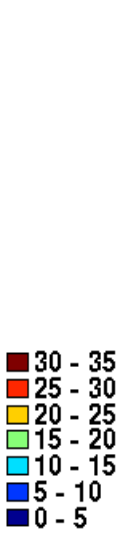

$0-5$

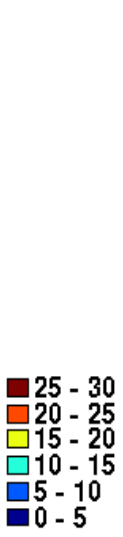

d) South $48 \mathrm{~N}$ Summer
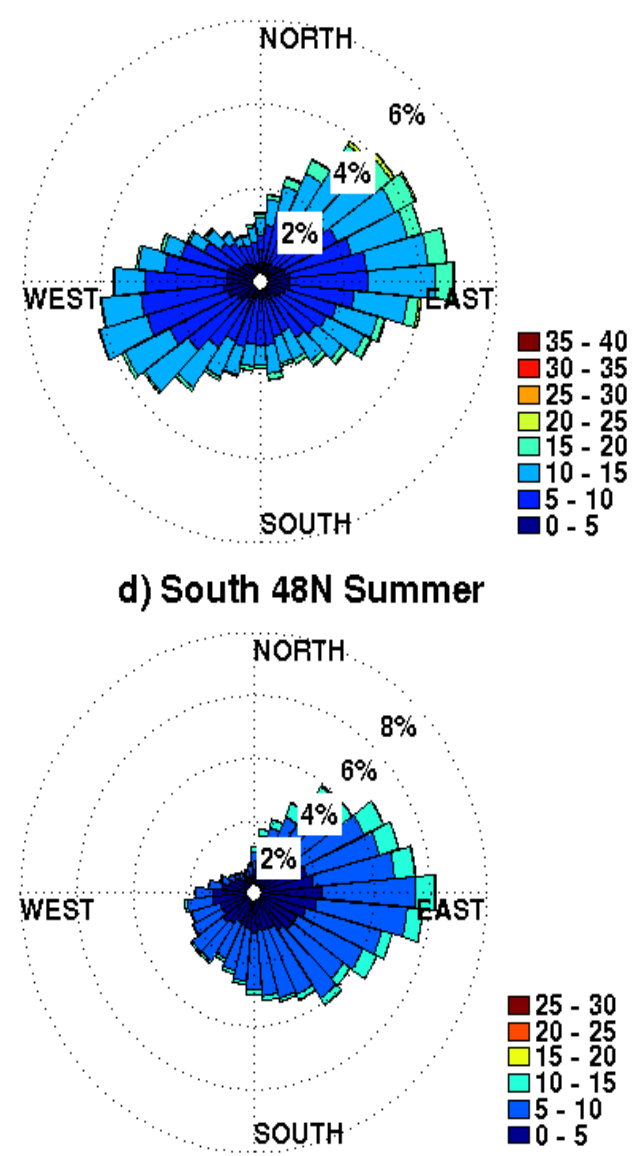

826

82Figure 6: Wind roses derived from scatterometer retrievals during the period January 2000 -

82December 2012. Figure 6a and $6 \mathrm{~b}$ indicate the results obtained from data occurring in north $40^{\circ} \mathrm{N}$ for ${ }_{82}^{82}$ winter and summer seasons, respectively. Figure 6c and 6d illustrate similar results for data occurring $831^{n}$ south $48^{\circ} \mathrm{N}$

832

833

834

835

836

837

838

839

840

841

842

843

844

845

846

847

848

849

850

851

852

853

854

855

856 

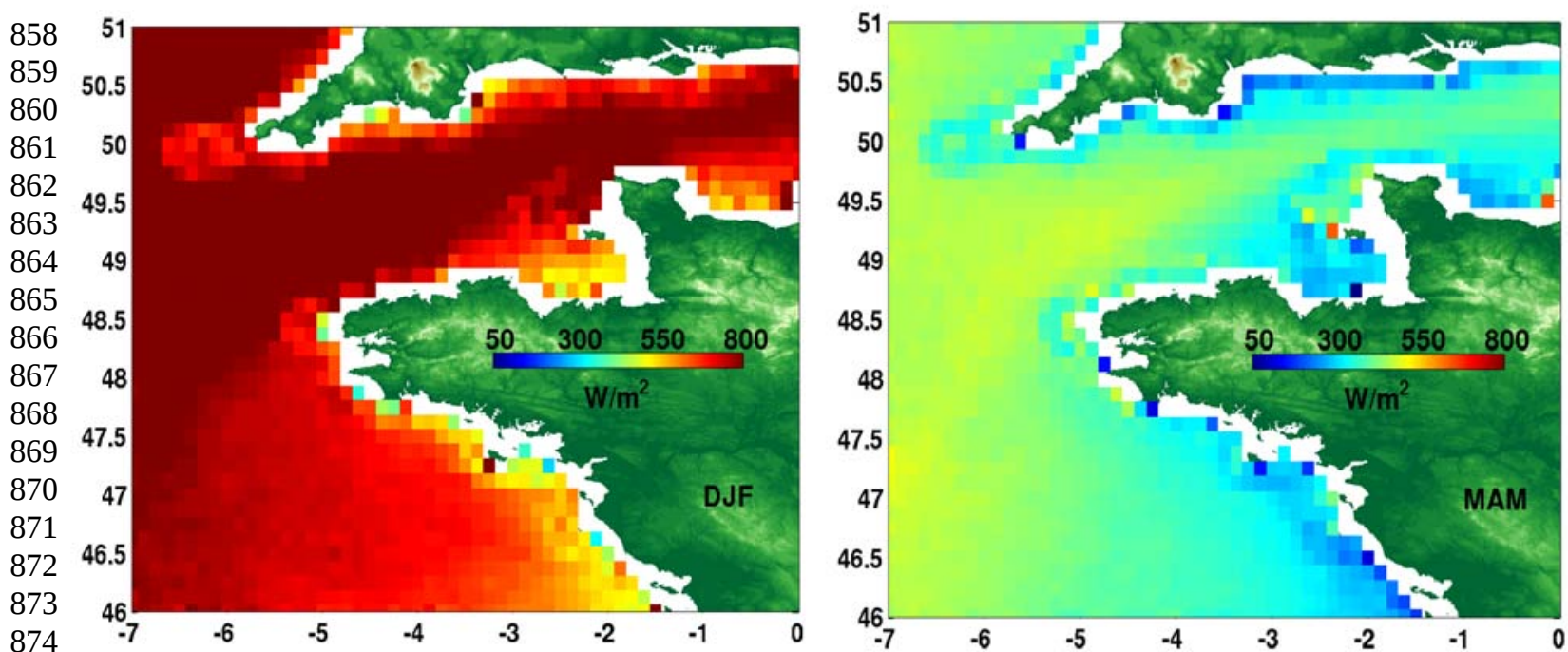

875

876

87750.5

$879 \quad 50$

880

$881^{49.5}$

882

883

88448.5

885

886

88747.5

888

889

$890 \quad 46.5$

891

892
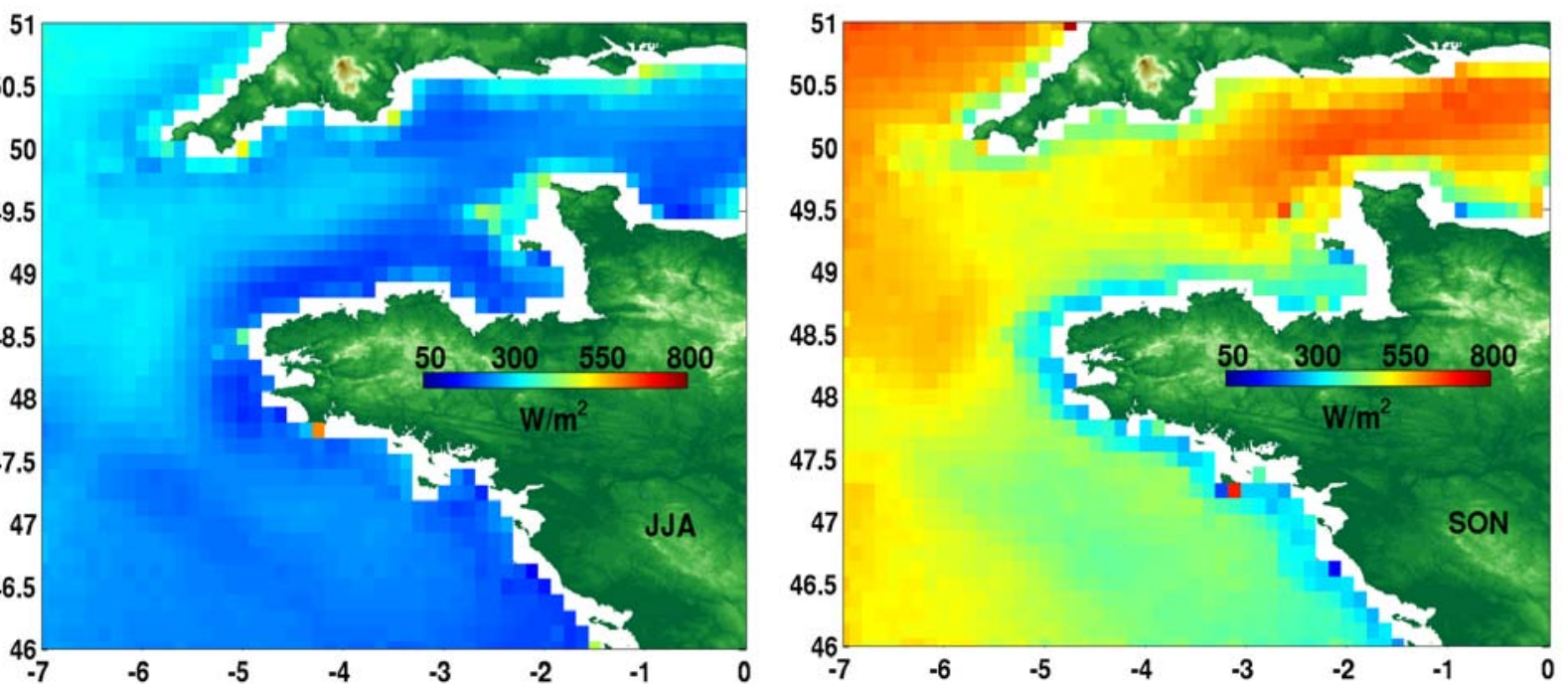

8\%igure 7: :Seasonal mean wind power (in color) estimated from scatterometer retrieval distributions during 894 the period January 2000 - December 2012 
899

900

901

902

903

904

905

906

907

908

909

لس 910

911

912

913

914
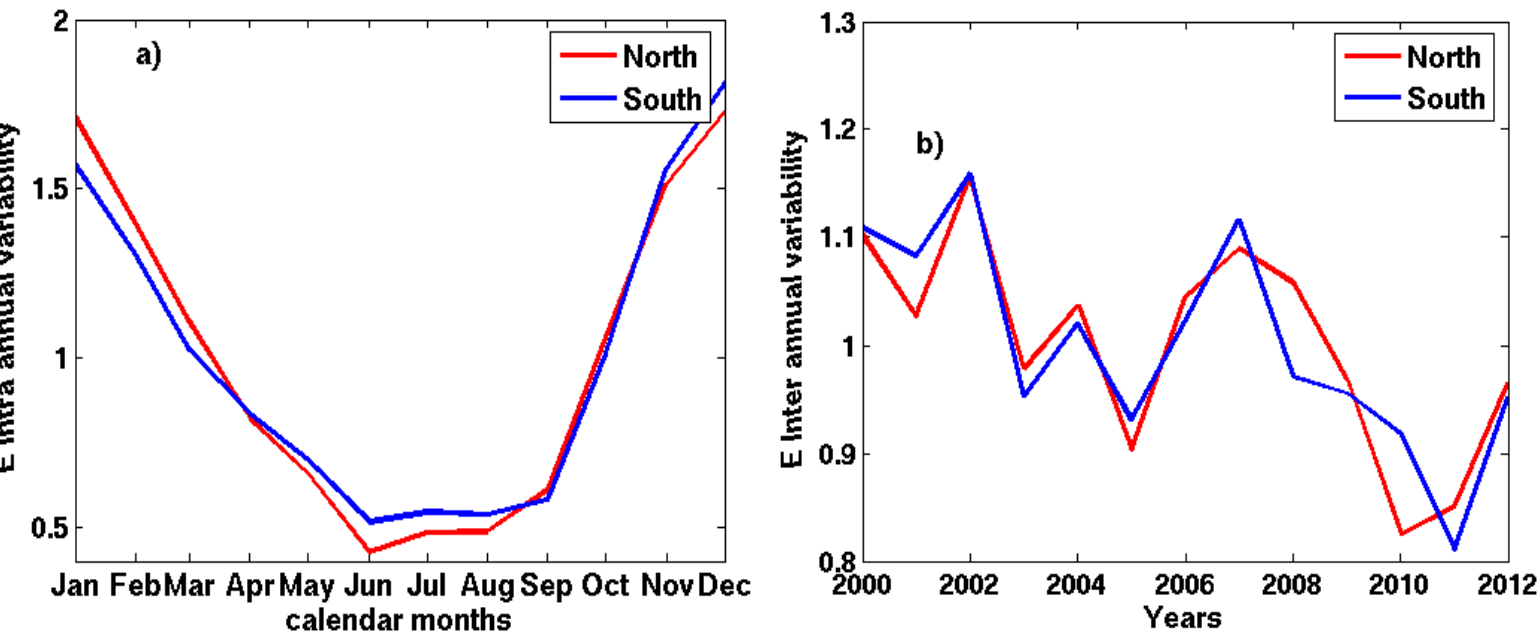

915igure 8: Intra-annual (Figure 8a) and inter-annual (Figure 8b) of wind power estimated from 916scatterometer retrieval distributions during the period January 2000 - December 2012

917

918

919

920

921

922

923

924

925

926

927 